\title{
Torgov Cyclization
}<smiles>C=CC1(O)CCCc2cc(OC)ccc21</smiles>

Chemistry in

Medicine and

Biology

\section{Key words}

steroids

asymmetric synthesis

disulfonimide

1. $\mathrm{Pd} / \mathrm{CaCO}_{3}, \mathrm{H}_{2}$ 2. $\mathrm{K}, \mathrm{NH}_{3}$

1:1 mixture of products

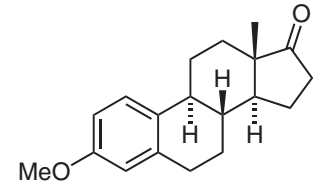

( \pm )-estrone methyl ether

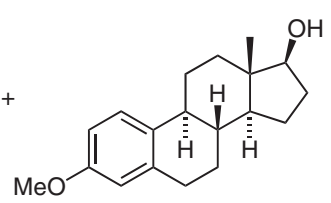

( \pm )-estradiol methyl ether

Corey and co-workers:

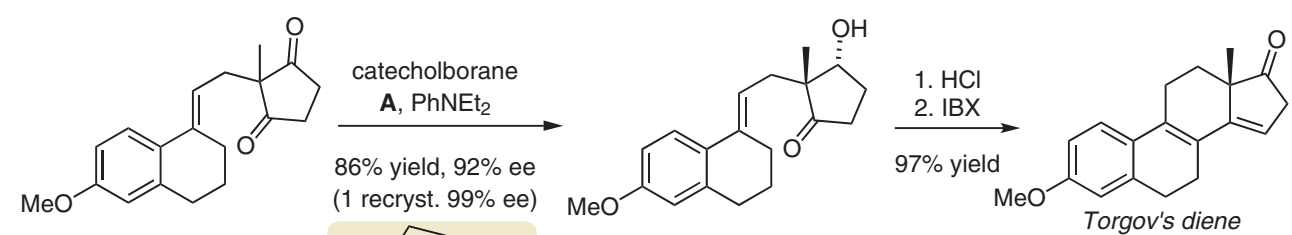<smiles>CCCCB1OC(c2ccccc2)[C@H]2CCCN12</smiles>

List and co-workers:
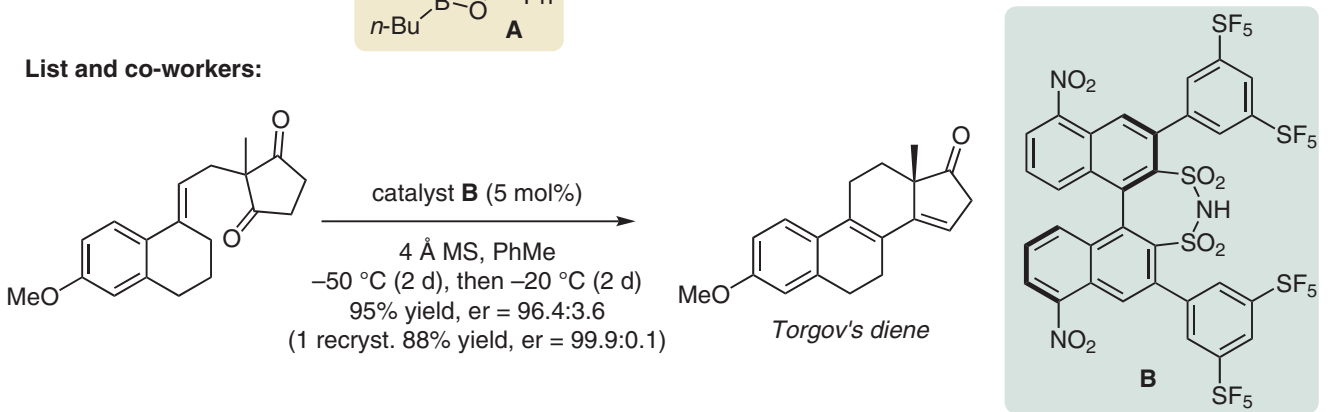

Significance: In 1963, Ananchenko and Torgov described the carbocyclization of an achiral diketone to give a tetracyclic intermediate (Torgov's diene) that provided an early pathway for the total synthesis of steroid hormones. This method has been used for the industrial-scale production of certain steroids. However, an enantioselective variant of the Torgov reaction has long remained elusive.
Comment: Corey and co-workers reported an enantioselective and diastereoselective reduction of the achiral diketone by using an oxazaborolidine catalyst A (J. Am. Chem. Soc. 2007, 129, 10346). Treatment of the mono-ketone with methanolic $\mathrm{HCl}$ followed by IBX oxidation gave Torgov's diene in high optical purity. List and co-workers developed a catalytic asymmetric Torgov cyclization using a novel dinitro-substituted disulfonimide catalyst B (Angew. Chem Int. Ed. 2014, 53, 8770). 